\title{
The Big Boom: What CIHR's Canadian Longitudinal Study on Aging Means to the Baby Boomer Generation and Canada's Healthcare System
}

While it may seem hard to believe, in less than a decade Canada's baby boomers will become senior citizens. Today, Canadians aged 65 and over represent $13 \%$ of the population. In 25 years, that number will increase to $21 \%$ (Statistics Canada 2002). No doubt, this will have a tremendous impact on Canada's healthcare system. Total health expenditure per person in Canada was estimated at $\$ 3,164$ in 2000, and is expected to increase over the next couple of years (Canadian Institute of Health Information 2002).

While the Government of Canada's February 2003 budget outlines a substantial reinvestment in healthcare $-\$ 17.3$ billion over the next three years and $\$ 34.8$ billion over the next five (Canadian Federal Budget 2003) - as well as sustained federal support for health reform, questions still remain: Will it be enough? Can Canada's healthcare system handle the needs of our aging population in the future without bankrupting taxpayers? Are there other approaches we could take to reduce the burden of the aging population on our healthcare system, and improve the health and quality of our senior citizens?

At the Canadian Institutes of Health Research (CIHR), our mandate is to develop and support health research across all disciplines and to translate new knowledge into improved health for Canadians, more effective health services and products and a strengthened healthcare system.

Efforts to turn research into action are spearheaded by CIHR's 13 institutes that partner with researchers, universities, hospitals, industry, governments, communities, charities and patient groups across Canada to develop innovative programs that will lead to a cost-effective Canadian healthcare system. This approach - which was endorsed by both Commissioner Roy Romanow and Senator Michael Kirby has as its premise that sustained investment in health research is a means to ensuring a sustainable and evidencebased healthcare system.

Research is the foundation of a healthy population and an effective healthcare system. Through new discoveries, treatments and interventions and a better understanding about how best to organize, finance and deliver health services and policies, research holds the best promise to strengthen the healthcare system, improve Canadians' health and quality of life and reduce the economic burden of illness.
Compared to other health issues, research on agingrelated ailments such as Alzheimer's disease and functional decline is currently underdeveloped. Today, cognitive decline, such as Alzheimer's and other dementias affects one in four Canadians over the age of 65 . With the dramatic increase of this age group by 2026 , the number of cases is expected to reach epidemic stages. And apart from known ailments, there is not enough scientific data today to enable us to correctly predict the healthcare needs of future older Canadians.

Clearly, research on aging needs to be at the top of the research priority list if we are to understand and address the impact our aging population will have on hospitals, patients, caregivers, practitioners, health researchers, nurses and, ultimately, policy-makers and taxpayers.

To address this research gap, CIHR's Institute of Aging, along with other CIHR Institutes, Health Canada, the Canadian Association of Gerontology, Statistics Canada, the Canadian Institute of Health Information and private sector representatives, have launched the Canadian Longitudinal Study on Aging (CLSA).

Researchers will be able to assess factors associated with healthy aging, the aging process, as well as risk factors for diseases and disabilities. The CLSA will study the causes and evolution of the most prominent diseases associated with aging including cancer, Alzheimer's and diabetes, and is expected to identify preventative strategies that will translate into practices, services and policies for Canadians. In other words, the CLSA will not only help Canada's aging population maintain better health, but it is expected to help provide improved, more cost-efficient treatment and programs that can translate into savings for taxpayers.

CIHR has identified this study as one of its nine crosscutting, transdisciplinary strategic initiatives for health research. CIHR's President, Dr. Alan Bernstein, has emphasized that it is crucial for people from all health research fields to break down silos and work together to educate policy-makers and effect positive change.

The CLSA will translate into useful data for policymakers, clinicians and researchers. It will effectively help policy-makers address the incidence and prevalence of diseases and disabilities, needs of elderly people, patterns 
of healthcare services utilization, social determinants of health, health promotion and disease prevention strategies, among other things. Clinicians will find the results useful in the areas of incidence and risk factors of diseases, patterns of care and drug utilization.

Since the CLSA is a large and complex initiative, before it can begin, a team of researchers must design a blueprint or protocol - for the study. Over $\$ 445,000$ was approved by $\mathrm{CIHR}$ and Health Canada for this protocol design. The protocol will be led by three principal investigators: Dr. Susan Kirkland from Dalhousie University, Dr. Parminder Raina from McMaster University and Dr. Christina Wolfson from McGill University, along with a team of 160 researchers across Canada. To start the process, a national workshop has already been held to identify research questions for the CLSA and parameters that should be included in the protocol. Once completed, the study protocol will be submitted to an international review board for approval in March 2004, with research set to begin later that year.

Underlying the CLSA is the recognition that transforming our healthcare system and the health of Canadians is not just about more dollars - it is about doing things differently. The CLSA will break down many silos of health research independence and transform Canada's healthcare system into one founded on evidence-based research. Hospitals, primary healthcare workers, clinicians and researchers will benefit from the CLSA results. But Canada's aging population will feel the biggest positive impact. Baby boomers, including myself, can take comfort in the realization that there will be no healthcare apocalypse on the horizon.

\section{References}

Canadian Federal Budget. 2003. www.fin.gc.ca/budget03/mm/ shock/mm_e.html. Accessed April 2003.

Canadian Institute for Health Information. 2002. secure.cihi.ca/ cihiweb/dispPage.jsp?cw_page=media_18dec2002_2_e. Accessed April 2003.

Kirby Committee. 2002. www.parl.gc.ca/37/2/parlbus/commbus/ senate/com-e/soci-e/rep-e/repoct02vol6-e.htm. Accessed April 2003.

Romanow Commission. 2002. www.healthcarecommission.ca/ Suite247/Common/GetMedia_WO.asp? MedialD=11.89\&Filename= HCC_Final_Report.pdf. Accessed April 2003.

Statistics Canada. 2002. www12.statcan.ca/english/census01/ release/index.cfm\#doctop. Accessed April 2003.

\begin{abstract}
About the Author
Dr. Réjean Hébert is the founding Scientific Director of the ClHR Institute of Aging. A medicine doctor, his research relates to functional decline in seniors (epidemiology, health services). Dr. Hébert developed and validated the Functional Autonomy Measurement System (SMAF), a disability rating scale widely used in Canada and other countries for clinical and research purposes. He has published more than 100 research papers in international journals and is associate editor of Précis pratique de gériatrie, a French-language textbook on geriatrics.
\end{abstract}

\section{ON-LINE www.longwoods.com}

Longwoods.com has been covering SARS resources and West Nile resources. Both sites are assiduously updated and cover administration, published papers and all the daily reports from recognized authorities. We provide no editorial comment; just a selection of sites. Go to www.longwoods.com and log on to SARS Update or WEST NILE Update

$>$ McGill has been collecting published papers as they relate to SARS. In this era of real-time research and realtime publishing (including peer reviews) a spectacular number of papers are available. Go to: www.health.library. mcgill.ca/resource/sars.htm\#journal

The increased use of the web to exchange knowledge and information is probably driven by the reduced amount of travel and face-to-face meetings following 9/11, the Iraq war and the SARS attack. Longwoods, for example had more than 900,000 hits in February, March and April from more than 50,000 visits - substantial increase from a year ago.

- Two journals - Electronic Healthcare and Nursing Leadership - are available online on an enterprise-wide basis using IP authentication. This requires no username or password. For more information please contact Susan Hale at shale@longwoods.com

- Hospitals are submitting profiles for publications by Longwoods. These cover either their organizations or specific programs. For an online version go to: www.longwoods.com/jobsite/profiles.html

-International peer review is now available from the Longwoods Review. The first paper examines a work disruption strategy from physicians in British Columbia. Go to the Longwoods Review at: www.longwoods.com/ opinions/index.html

Canada's internet pharmacy works because it has not succumbed to cheap publicity - only thoughtful information on topics their consumers have indicated an interest in. For more information about such diverse issues as Attention Deficit Disorder; Excessive Sweating (Hyperhidrosis; Antabuse (Disulfiram); and HIV/Aids Resources go to: www.pharmacy.ca/htopics.shtml

Ontario Hospital Association conferences are not limited to members. Many visitors from coast to coast take advantage of their comprehensive program. Visit www.OHA.com and follow the links. 